\title{
From Disaster to Resilience
}

What is changing in the world so that the word "resilience" is so frequently used? 2015 marks the ten year anniversary of Hurricane Katrina and the five year anniversary of the Gulf of Mexico oil spill. The Gulf Coast Community Design Studio has been working on the Mississippi Gulf Coast since Hurricane Katrina and their work provides the vantage point of this paper. The Gulf Coast Community Design Studio is an off-campus research and service center of Mississippi State University College of Architecture, Art and Design located in Biloxi, Mississippi. It was created to respond to Hurricane Katrina and has evolved from disaster response to long-term efforts of resilience. The design studio's evolution is not an isolated story. It is part of a national move toward resilience.

The diagram below depicts the relationship of risk and awareness of risk. Risk is steadily increasing because natural hazards are increasing and because our increasingly urbanized, industrialized, global economy is dependent upon systems that are vulnerable to failure. However, even though risk is increasing at a steady rate, the awareness of risk changes abruptly with events such as Hurricane Katrina, the Gulf of Mexico oil spill, Super Storm Sandy, etc. Such disruptive events change the public's attention to risk and stimulate cooperative work. The shaded zone is the working space of resilience and can be thought of as the work to cooperate risk.

As disruptive events happen more frequently and effect more people the public's awareness of risk remains heightened and becomes a concern that doesn't go away. Such is the condition of the twenty-first century, a condition in which there is a nagging awareness of increasing risk. Such awareness has an emotional dimension, especially when we consider that natural hazards are uncertain and images of disaster in some other part of the world remind us that the particular place we call home could be hit next. In the context of risk, the word "resilience" is used to counteract uncertainty. It stands against uncertainty and even though we do not know precisely what we are going to do to become resilient we agree that we should be doing something.

In the ten years since Hurricane Katrina the work of MSU's Gulf Coast Community Design Studio has paralleled a national move toward resilience. Their work has been part of a series of national programs and sources of funding that mark a path from disaster recovery to resilience. The design studio's work and the parallel national path toward resilience include:
DAVID PERKES

Mississippi State University 


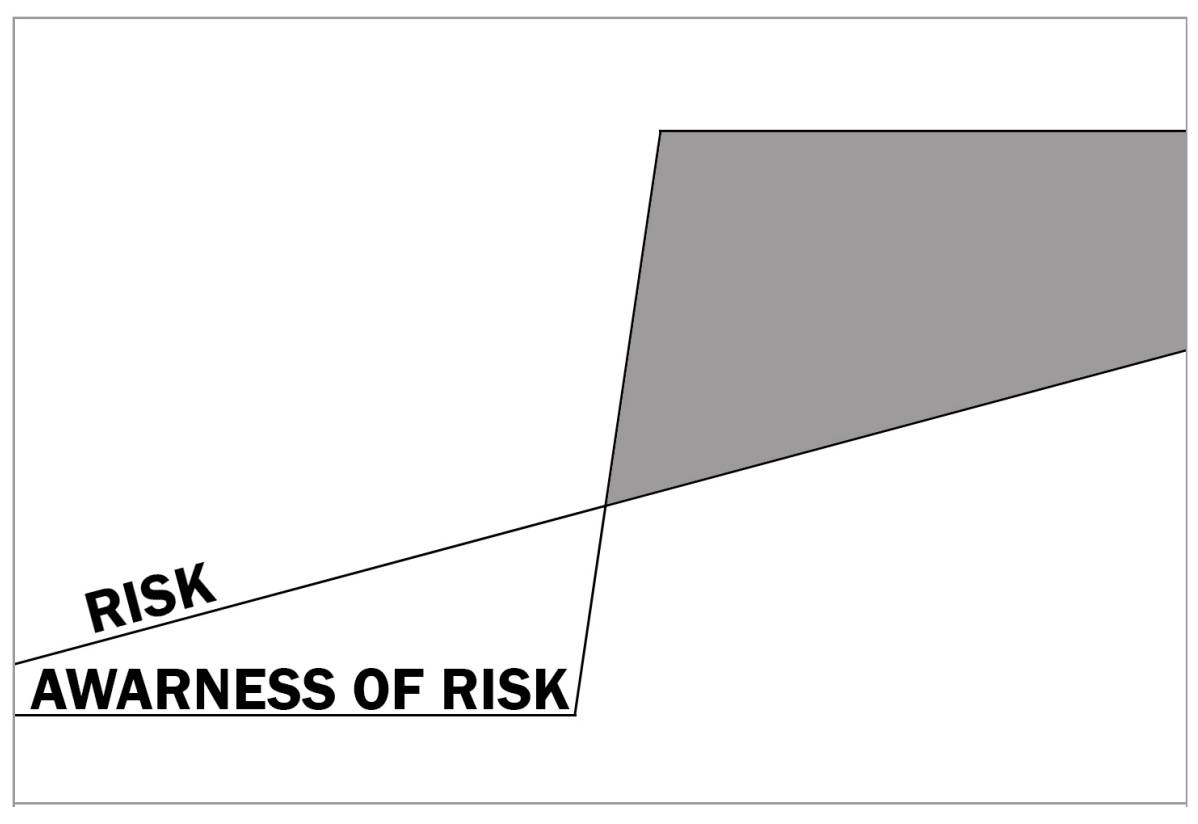

- 2006-2009 - HUD Rebuilding America Partnership Grant.

- 2008-2012 - HUD Community Development Block Grant Disaster Recovery funding to produce Long Term Work Force Housing to replace houses lost in Katrina.

- 2009-2012 - Department of Homeland Security South East Region Research Initiative (SERRI) funding to research Flood-proof Construction and Temporary Disaster Housing.

- 2010-2015 - National Fish and Wildlife Foundation funding for inner city tidal marsh restoration following the BP Gulf of Mexico Oil Spill.

- $\quad$ 2010-2013 - HUD Sustainable Communities Initiative.

- $\quad$ 2013-2014 - HUD Rebuild By Design

- 2014-2015 - HUD National Disaster Resilience Competition

Four resilience lessons from the work of the Gulf Coast Community Design Studio stand out: realism, collaboration, information, and design.

\section{REALISM}

The word "resilience" was not a noticeable part of the work on the Gulf Coast In the first few years following Hurricane Katrina. Other words were common such as "rebuilding, recovery, renewal, Renaissance," all words that pointed to a return to at least a prior condition and hopefully to a better version of the past. From a ten year vantage point the official language used soon after Katrina shows a remarkable idealism and an effort to simplify the traumatic loss and confusion.

Within weeks of the disaster, under the effective leadership of Governor Haley Barbour, Andres Duany with the help of architects and planners from around the country associated with the Congress for the New Urbanism were enlisted for an unprecedented planning effort officially called "The Governor's Renewal Forum" but commonly referred to as the "Governor's Charrette." It is safe to say there has never been such a gathering of planning professionals brought in and put to work in such a place in such short order. Over 100 
architects, planners, engineers and other professionals from outside the state were joined by nearly the same number of local professionals. The charrette took place in the middle of October, just six weeks after the storm. The work space was in one of the shuttered casino hotels already busy with contractors working to get the casino back on line. Outside the improvised workspace, the damage on the coast was stunning and destroyed areas were still under military guard. The contrast between lovingly rendered drawings being pinned up inside the hotel, and the view just outside the hotel of a massive four-story casino barge smashed into the side of the hotel's parking garage was almost impossible to reconcile.

Words from the opening pages of the Governor's Commission Report characterize the idealism of the planning effort:

"Throughout the Renewal Forum and the work of the Commission, South Mississippi has been referred to as a "clean slate," providing an enormous opportunity to rebuild in a way that optimizes the natural beauty of the Gulf Coast. Nowhere is this statement more accurate than with regard to the Highway 90 corridor. Hurricane Katrina's winds and flood waters destroyed most, if not all, of the existing structures along this corridor. From Waveland to Pascagoula, the structural remains can be described as a fresh canvas awaiting a skilled artist's creativity." ${ }^{\prime 1}$

Nearly ten years later, it is difficult to not cringe at words such as "clean slate" and "fresh canvas" considering the reality of the Mississippi Gulf Coast. Even though the lots cleared of houses by the storm surge appeared to be open land ready for development, the thousands of property owners that lost their houses still owned the property. Furthermore, this far-from-clean slate became much messier as the FEMA flood insurance rate maps were drastically revised, flood and wind insurance shot up to exceed the cost of many homeowners' mortgages, policy changed to allow casinos built on land, and accordingly, anticipating a booming tourism and casino market, cities along the coast re-zoned residential property into water-front development, resulting in a highly speculative real estate market. Thus, the fresh canvas that only lacked the artist's touch in the idealism of renewal was in reality a very confusing and difficult place to build. Even though the open land looked simple, the underlying conditions of uncertainly had dramatically increased. Uncertainty increased further with the 2008 recession, which for the most part took away the casino and condominium market, followed by the 2010 oil spill, which for a time took away much of the tourism and commercial fishing market.

Soon after the storm the Gulf Coast Community Design Studio started working in East Biloxi, setting up an improvised workspace on the second floor of a church building that had been temporarily transformed into a coordination center. East Biloxi is an historic, low-income community in an area four miles long and one mile across at the tip of the Biloxi peninsula. Most of the peninsula is less then twelve feet above sea level, and it borders on the Gulf of Mexico to the south and the Back Bay to the north. Hurricane Katrina's unprecedented storm surge, which was well over twenty feet in Biloxi, inundated the entire peninsula, affecting every house. When the water subsided, nearly half of the existing four thousand houses had been completely destroyed and the other half had been flooded.

The design studio's first community assistance illustrates the lesson of realism. East Biloxi was a confusing place to work with overwhelming needs of a traumatized community and hundreds of volunteers who came to help. To help communicate and coordinate the relief and clean-up efforts the design studio produced what became known at the "grid map," dividing East Biloxi into 24 numbered blocks. Stacks of the color grid maps, reproduced on $11^{\prime \prime} \times 17$ " paper, were used by dozens of organizations to plan and distribute relief and rebuilding activities. The relatively simple task of making a useful map had a magnified impact. The primary function was coordinating relief activities, but there were two 
byproducts of the grid map. First, the community looked at the map and was able to envision an organized relief effort at a time when everyone felt overwhelmed and confused, focusing the community's attention on the East Biloxi Coordination and Relief Center as the place where help could be found. The second byproduct was the way the grid map introduced the community and relief organizations to the Gulf Coast Community Design Studio. Many people in the community were already suspicious of outside planners because of the Governor's Charrette. Despite the charrette's positive publicity and support from state leaders, many residents were upset that they had been left out of the process and were offended that a planning firm from California was producing idealized images of "what East Biloxi could look like." The fact that the Gulf Coast Community Design Studio simply made clear and useful maps that provided realistic information was important to gain the community's trust. Following the aim of realism the design studio produced many maps, including flood maps to explain the confusing FEMA advisory flood levels, maps showing the disproportionate impact of the hurricane damage on Biloxi's Vietnamese community, maps showing the change of policy for casinos now allowed to be built within 800 feet of the coast line, and others. The community soon came to know that the Gulf Coast Community Design Studio has the expertise and engagement with the community to produce useful maps.

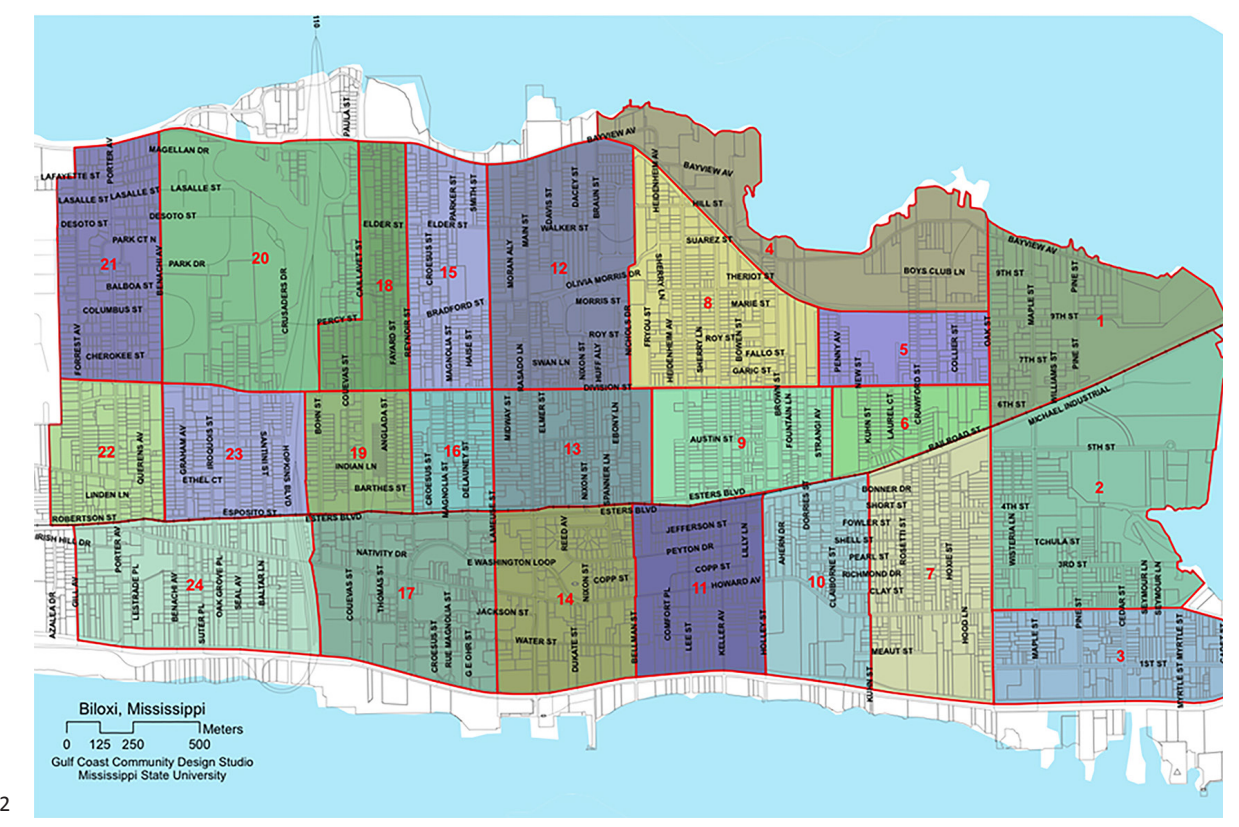

The mapping work led to several neighborhood planning projects in which the design studio took an asset-based approach, showing the community what they have to work with and helping them make realistic decisions. In practice, resilience planning asks the questions: What are the community's existing strengths and vulnerabilities? What risks are anticipated in the future? What can be done to address the vulnerabilities and prepare for future risks? Such questions require a community to be willing to be realistic and require planners to be willing to listen and not find themselves producing images of the future that might look appealing but are too far from reality to be useful.

\section{COLLABORATION}

The overwhelming needs of a disaster and the equally confusing resource of volunteers and assistance programs lead to an unusual degree of collaboration. From its beginning the Gulf Coast Community Design Studio has collaborated with dozens of community partners. The obvious need to collaborate in response to Hurricane Katrina led to long-term cooperative relationships that have effectively evolved into the work of resilience. Resilience 
at the scale of a city can only be imagined with the same high level of collaboration that is required for disaster recovery. This collaboration is vertical and horizontal: vertical, in that the interrelated parts in the line of action from localized need up to the federal agency or foundation aiming to address the needs are coordinated; and horizontal, in that parallel activities that might normally compete and neighboring organizations that might normally define their work narrowly learn to cross boundaries and work with each other.

The Gulf Coast Community Design Studio has proven the effectiveness of both vertical and horizontal collaboration. The staff consists of architects, planners and landscape architects working on a broad range of projects in collaboration with many community partners. The design studio operates with grants and contracts as an off-campus research center through the university's Office of Sponsored Programs. However, their work environment looks more like a design firm than a research center; and their projects have as much outreach and design work as research. Every project has community partners, multiple partners in most cases, and all the work is shaped by a commitment to engage the public. This commitment stems from both social justice values and from a pragmatic approach to achieve better results.

The lessons of collaboration and its role in resilience are demonstrated in two design studio projects: Katrina replacement houses and Bayou Auguste restoration.

Hurricane Katrina resulted in overwhelming housing needs in cities along the Gulf Coast. The Gulf Coast Community Design Studio's response was shaped by three realizations. First, design services alone would not be effective and needed to be part of a comprehensive case management approach. Second, to ensure long-term impact, families that are going to live in the houses should be included in the design process so that the resulting houses are a good fit. Third, the construction labor force after a large disaster consists of inexperienced volunteers, changing site supervisors, builders who might not understand hurricane zone construction and other unusual situations so the architect's role during construction is different than for a typical contractor project.

For eight years, with various funding sources, the Gulf Coast Community Design Studio provided architectural services for over 230 new houses and over 100 rehabilitated houses. Each house was designed specifically for the family and site. The design studio worked with seven primary partner organizations: The East Biloxi Coordination and Relief Center, which was renamed Hope Community Development Agency; International Relief and Development (IRD), which evolved into Climb Community Development Corporation; The Biloxi Housing Authority; Hancock Housing Resources Center; Back Bay Mission; Habitat for Humanity Gulf Coast, and Habitat for Humanity Bay-Waveland. Each partner organization did the work on either side of the design studio work: case management leading up to design, and construction management to get the houses built. In all cases the design studio provided architectural services for low-income households that qualified for various assistance programs.

The project organization and contract arrangements were designed to support effective collaboration. Vertical collaboration was facilitated in the way the design studio was paid. Under three different agreements utilizing HUD funds the Gulf Coast Community Design Studio was directly paid to provide architectural services to multiple non-profit building organizations. The homeowners, all of whom were getting assistance, were not required to pay for design services. What's more, the seven partners mentioned above did not need to include design services in their budgets, because those cost were covered from HUD through the state to the design studio. This allowed the design studio to manage their own work and create a method that efficiently repeated construction details but was able to develop individualized floor plans, site plans, kitchen layouts, porches, etc., with extensive 


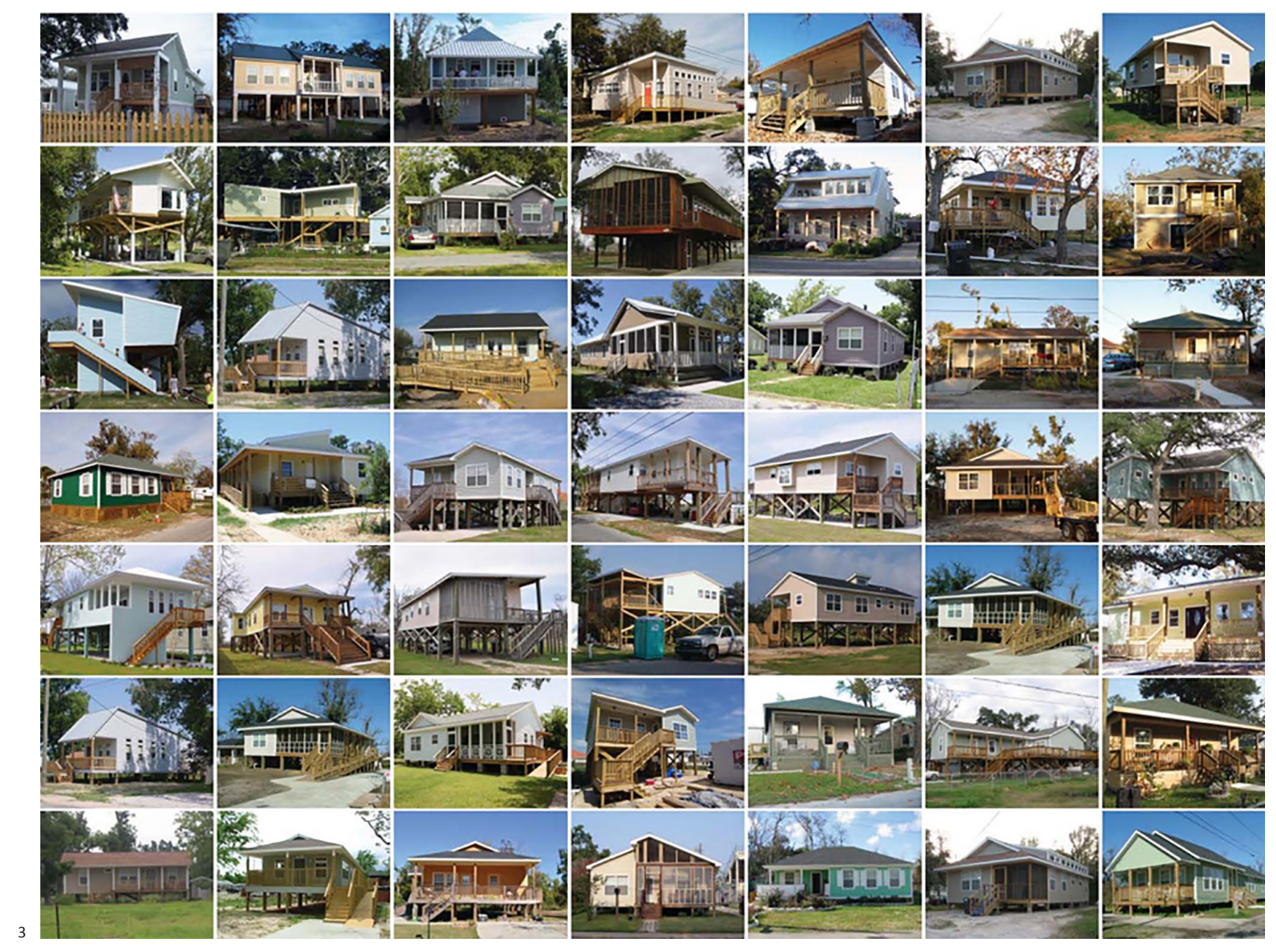

homeowner involvement. This design-driven approach created houses that have been well received by the community and are likely to be houses that families will commit to and pass on to their children, thus helping to restore and sustain neighborhoods that were impacted by Hurricane Katrina. The sample of completed houses below illustrates the range of designs, evidence that the homeowners' decisions significantly shaped the designs.

Horizontal collaboration between the design studio and their partners was made possible by long-term cooperative relationships, reinforced by the fact that the partners did not pay for design services so that the design studio's commitment to the project was never reduced to a debate about fees. The horizontal collaboration was especially apparent in that the Gulf Coast Community Design Studio put their workspace in the same building as the East Biloxi Coordination and Relief Center to allow ongoing, day-to-day communication with the case managers, construction coordinators, and the hundreds of East Biloxi residents that came into the center. The homeowners going through the assistance process experienced the design studio as part of what the community called "The Coordination Center," not as a separate university program.

The Bayou Auguste restoration project collaborated with multiple community partners to transform a degraded tidal stream into a resilient landscape, creating a public asset for a historically underserved community. The project is part of a community plan for East Biloxi, a low-income, racially-mixed community devastated by Hurricane Katrina. The Gulf Coast Community Design Studio secured multiple grants, leading a partnership including the City

Figure 3: Katrina Replacement Houses 
of Biloxi, Biloxi Housing Authority, Biloxi Public School District, and the Land Trust for the Mississippi Coastal Plain, to leverage grant funds and volunteer labor.

The bayou's wetland habitat had been seriously impacted over time. Its natural, meandering course was straightened, forming a steeply cut channel that degraded the bayou's function and aesthetic appeal. To reveal the site's social and ecological potential, the project reshaped the stream banks to create tidal marsh habitat and opened views into the constructed wetland. Local volunteers contributed over 3000 hours of service and participated in the construction of the project, removed debris, installed erosion control materials, and planted native plants.

The design studio engaged the local community and students through educational programs focusing on ways to improve the bayou's important functions including: 1) restoring and improving nursery habitat for fish and shrimp, essential to the local economy; 2) reducing pollution and debris entering the ocean through the integrated bayou and storm water system; and 3) creating marshland to contain floodwater from extreme storm events. Bayou Auguste has an important social role allowing the community to enjoy wildlife, encouraging environmental stewardship and appreciating the unique coastal environment that makes Biloxi home. Collaboration with the community resulted in a project in which both the process and the outcome increased community resilience by improving the natural water system and by increase environmental stewardship.

\section{INFORMATION}

Resilience comes from changing the way we imagine the future and acting on plans to alter and adapt to a future with increased risk. Information is essential to shape the imagination and make plans to become more resilient. Resilient information includes research to understand risks, vulnerabilities and actions to prepare for risks, information technology to help people comprehend and form values around resilience, and cooperative decision making efforts to apply information to plan alternatives.

Before "resilience" was such as well-used word, "sustainability" made a well-worn path, changing the way we think about how our current actions relate to our consumption of energy and impact human health and the environment. The costs of energy, health and environmental services impacted by our actions can be calculated and formulated with the costs of better systems, materials and practices. Thus sustainability has an economy that has successfully created a market. Resilience, on the other hand, depends upon a prediction of future loss and requires a more difficult calculation of how our actions today can reduce the cost of future losses. Resilience does not yet have a simple cost-benefit approach in the way sustainable practices, most of which save energy, have a predictable pay-back period. This complexity is because the background condition is changing because risks are increasing, but forecasts of how risks are increasing are complex and controversial. Therefore, resilience information is challenging and is often shaped by emotions. It requires a sort of faith that is more akin to traditional agriculture than to mechanical production. At the time of planting, the value of a future harvest is uncertain because it depends upon weather and the market; likewise, resilience is uncertain because it depends upon climate and the timerelated effects and side effects of natural and human-made systems. Nevertheless, in the same way that twentieth-century agri-business counteracted the uncertainty of tradition agri-culture with a host of insurances and market controls, predicting and investing in future risks will undoubtedly improve as informational and predictive formulae advance, eventually replacing faith with global financing. In the meantime, however, especially at the scale of a city, resilience plans are moved by faith that actions taken today are worth the cost of uncertain future conditions. 
The Gulf Coast Community Design Studio is working with resilient information at several scales. The smallest is the scale of a house. With the many houses that the design studio collaborated to design and build came expertise in building for hurricane hazards. During the rebuilding in the first few years following Hurricane Katrina the design studio developed wood frame construction details and sheer wall designs for dozens of houses. The architects and interns explained the structural rationale to many builders and building inspectors, since many of the builders were from parts of the country without high-wind zones and because the Gulf Coast municipalities well all getting to know the recently adopted International Building Code. In 2010 the Gulf Coast Community Design Studio worked in partnership with the Community and Regional Resiliency Institute to put on a training program. The design studio taught several classes about resilient wood frame construction to architects and builders. In addition they built full-size constructions of house framing showing framing, sheathing and finish.

In the first few years after Hurricane Katrina the focus was on high-wind construction as an engineering issue and there was not a national program to provide financial benefits to home owners. However, in 2010 the Fortified Home program was introduced from the Institute for Building and Home Safety (IBHS). The Gulf Coast Community Design Studio was well positioned to inform the community about this program and has been working with IBHS to educate and promote Fortified Homes. They are currently working with a partner organization to administer a homeowner assistance program for low-income families to be able to get a low-interest loan to make improvements that can save as much as $20 \%$ on their homeowners insurance. In addition to the work with IBHS the Gulf Coast Community Design Studio recently completed a project in partnership with the Federal Alliance for Safe Homes (FLASH) to produce a Resilient Home Building Guide. Such work directly informs design professionals, builders and homeowners about ways to make houses more resilient.

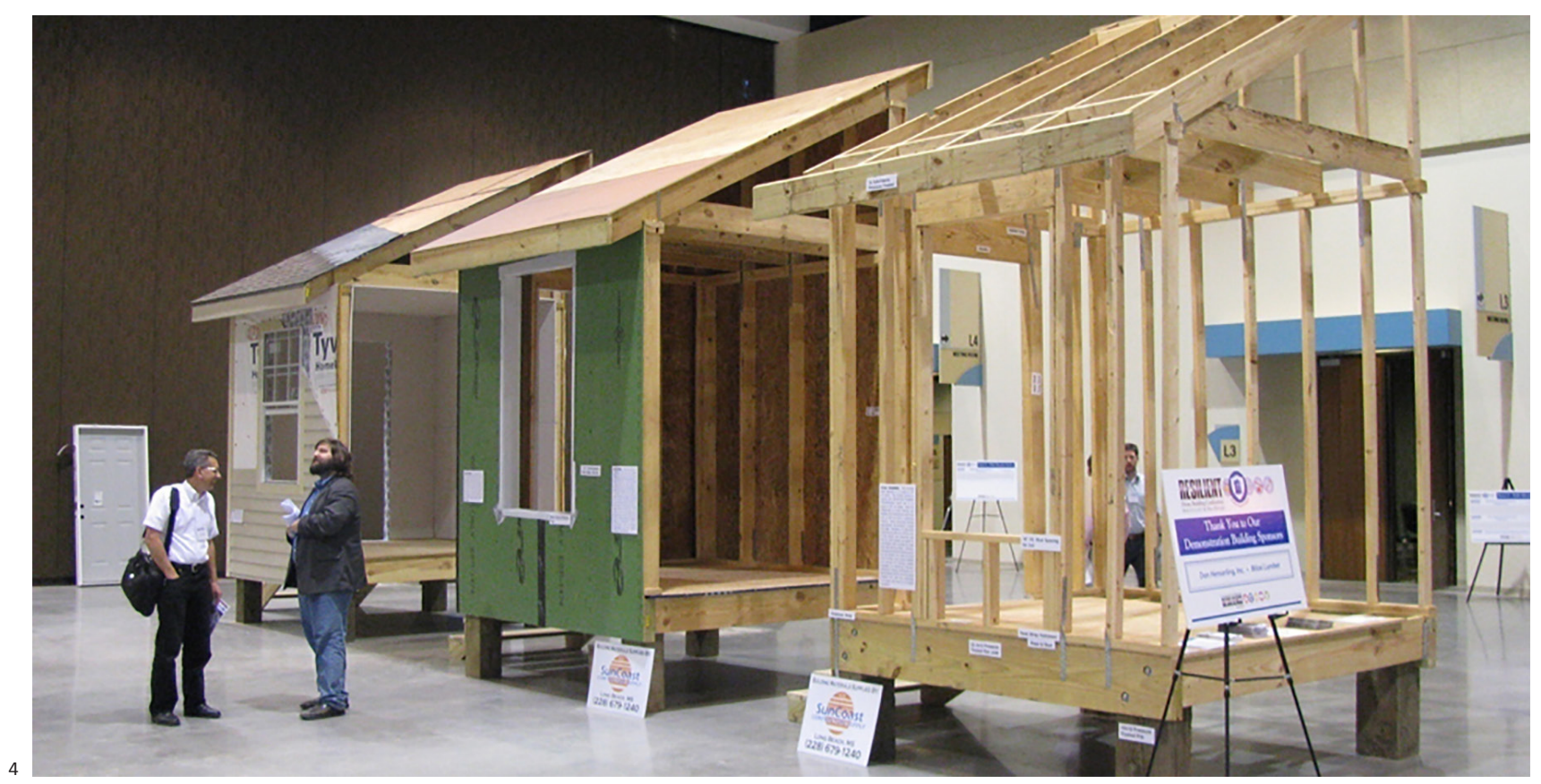

\section{DESIGN}

Rebuild By Design is a national competition announced by HUD in the summer of 2013 to invite design teams to work in cities affected by Hurricane Sandy. The Gulf Coast Community 
Design Studio was part of one of ten teams that were selected to participate in the design competition. As the name suggests the teams were given the charge to lead by design and to work with communities to come up with innovative proposals to address the risks that Sandy made apparent. It is significant in the national move toward resilience that the discussion around Sandy was noticeably different from the discussion in the years after Katrina. Resilience was the primary viewpoint of Rebuild By Design and proved to be an effective way to work with complex issues such as climate change and the vulnerability of aging infrastructure. The output of Rebuild By Design and the importance it placed on the role of design set a positive direction for architects, planners and landscape architects to take a lead in shaping the work of resilience.

The national move toward resilience was clearly made manifest by the fact that during the Rebuild By Design competition period HUD's Office of Sustainable Communities was renamed the "Office of Economic Resilience." Furthermore, the first major initiative of the Office of Economic Resilience was the National Disaster Resilience Competition (NDRC), which makes reference to Rebuild By Design as a model of how cities and states can do better than recover from disaster by using design and planning to imagine and pursue resilience. The Gulf Coast Community Design Studio is currently working with state agencies and other partners to assist the Mississippi Governor's office in the National Disaster Resilience Competition application. It is encouraging that even in a politically conservative state, working under the umbrella of resilience allows a multi-disciplinary group of scientists, planners, architects, economists, social service providers, and policy makers to work on challenging issues such as climate risk, shoreline loss, social and environmental vulnerability and land-use planning.

Resilient planning requires a realistic representation of a future with increased risk and illustrated ideas showing how these risks can be addressed. Thus, resilience is a design effort. But not done by architects alone; resilience planning is a collaborative design effort, bringing together people in the same way that disaster response and recovery brings people together. As illustrated in the work of the Gulf Coast Community Design Studio the current, broadly defined term "resilience" offers an extraordinary opportunity for universities to work in partnership with professionals to advance multi-disciplinary resilience efforts. Furthermore, if the output of university programs is seen as being relevant to government and to the general public their work can shape resilience's vague definition to include the value of design.

\section{ENDNOTE}

1. Governor's Commission on Recovery, Rebuilding and Renewal, After Katrina: Building Back Better than Ever (Jackson: Office of the Governor, 2005), 21. 